\title{
Performance characteristics of fiber modified hot mix asphalt
}

\author{
L.M.G. Klinsky ${ }^{\text {a }}$, K.E. Kaloush ${ }^{\text {b }}$, V.C. Faria ${ }^{\text {a }}$, V.S.S. Bardini ${ }^{\text {c,* }}$ \\ ${ }^{a}$ Centro de Pesquisas Rodoviárias, CCR Group, Presidente Dutra Road, km 184.3, Santa Isabel, Brazil \\ ${ }^{\mathrm{b}}$ Department of Civil, Environmental and Sustainable Engineering, Arizona State University, P.O. Box 875306, Tempe, AZ, United States \\ ‘ Universidade Estadual Paulista “Júlio de Mesquita Filho", Instituo de Ciência e Tecnologia, Presidente Dutra Road, km 138.5, 12247-004 São José dos Campos, Brazil
}

\section{H I G H L I G H T S}

- The addition of fibers to hot mix asphalt enhance performance characteristics.

- Pavement overlays with fiber modified hot mix asphalt can better resist reflective cracking.

- Rutting is developed in all hot a mix asphalt, but the addition of fibers can reduce de rutting rate evolution.

\section{A R T I C L E I N F O}

\section{Article history:}

Received 21 February 2017

Received in revised form 25 April 2018

Accepted 27 April 2018

\section{Keywords:}

Asphalt mixture

Polypropylene fibers

Aramid fibers

Resilient modulus

Dynamic modulus

Flow number

Fatigue cracking

Reflective cracking

\begin{abstract}
A B S T R A C T
A mixture of polypropylene and aramid fibers was used in this study to evaluate the performance characteristics of a modified asphalt mixture. A conventional dense-graded hot mix asphalt (HMA) used in Sao Paulo, Brazil was used. The laboratory experimental program included the evaluation of: resistance of compacted hot mix asphalt (HMA) to moisture-induced damage, resilient modulus, dynamic modulus; flow number test; fatigue by flexural bending, and fracture energy using the semi-circular test. Two asphalt mixtures were used in the laboratory program: a control HMA with no fibers, and a fiber reinforced HMA, which contained the fibers. The data was used to compare the performance of the fiber modified mixture to the control. The results showed that the fibers improved the mechanical properties of the control hot mix asphalt. The use of polypropylene and aramid fibers in HMA could enhance the performance of asphalt pavements against common distresses as rutting, raveling, fatigue and reflective cracking.
\end{abstract}

(c) 2018 Elsevier Ltd. All rights reserved.

\section{Introduction}

Asphalt pavements deteriorate over time because of combined effect of traffic loading and the environment. The service life of asphalt pavements can even be cut short if quality materials are not used in the hot mix asphalt (HMA) design and manufacturing. A properly designed pavement will perform well during its design life, and the distresses will not exceed allowable limits.

The quality of the HMA materials used will also notably affect the performance. As quality materials are increasingly challenging to find, modified mixtures have been getting more acceptance. Different types of distresses can be identified in asphalt pavements during their service life, and they are caused by different factors. Moisture sensitivity is one of the factors that leads to premature failure of pavements. The presence of water in pavements can be

\footnotetext{
* Corresponding author.

E-mail addresses: kaloush@asu.edu (K.E. Kaloush),valeria.faria@grupoccr.com.br (V.C. Faria), vivian.bardini@ict.unesp.br (V.S.S. Bardini).
}

detrimental if combined with other factors, such as freeze-thaw cycling. A progressive disintegration of an HMA, called raveling, could be developed from the surface downward as a result of the dislodgement of aggregate particles. This distress can be associated to material selection and also poor compacted asphalt layers.

Rutting is another type of asphalt pavement distress. It is a longitudinal depression in the wheel path that can be also caused by shear failure of the bituminous concrete layer. Slow moving traffic and high temperatures facilitate the development of this type of deterioration.

Fatigue cracking is a major distress mode that causes premature failure in flexible pavements. This deterioration mode can affect pavement serviceability, structural capacity and appearance. It can be associated to poor pavement design, excessive repeated traffic loading and poor material selection.

Reflective cracking in asphalt pavements has been also a concern for many years. The primary cause of the reflective cracking is the differential movement of the pavement layers due to the stress produced by the traffic and the environment. 
The reflective cracks are common in asphalt overlays on cracked asphalt concrete pavements. The main problems of the reflective cracks are the infiltration of water into the lower layers, weakening the pavement as a whole; in addition to an increase in the maintenance time and costs and poor ride quality and service conditions [1].

Many studies and researches look for better materials and/or modifications that could enhance the characteristics of hot mix asphalt and reduce or eliminate the development of asphalt pavement distresses. Thereby, different types of fibers have been used in asphalt pavements to improve performance [2].

The addition of fibers to HMA can improve its fatigue and rutting-resistance properties [3]. The benefits provided by the use of fibers can be identified as following [4]:

- Helps to fix the asphalt binder in the mix and prevents draindown;

- Reinforce the mastic;

- Reduce temperature susceptibility of the mastic because of the 3D network created.

Carpet fibers, for example, may increase the fatigue cracking resistance of asphalt concrete [5], however, some types may not be compatible with asphalt binder. Carbon fibers stiffen the concrete asphalt and make it more resistant at high temperatures to permanent deformation and higher tensile strength, but at lower temperatures improvements may not be noted [6].

Glass fibers can increase stiffness and tensile strength of hot mix asphalt but they must be handled carefully during construction [7]. However, stability and stiffness reduction and increasing the voids in the mix have been reported [8].

Polypropylene fibers are extensively used in civil engineering, mainly in concrete as a three-dimensional secondary reinforcement. Due to adhesion between polypropylene fibers and bitumen, the strengthening mechanism in asphalt concrete is different [9]. These fibers can delay the reflective cracking caused by vertical and horizontal movements of underlying concrete slabs and reduce rutting development [10].

The most successful use of fibers in asphalt concrete mixtures has been a combination of polypropylene and aramid. The polypropylene would act as an adhesion and dispersing agent; whereas, the aramid provide the three-dimensional reinforcement. The combination of polypropylene and aramid fibers improve the performance of asphalt mixtures related to the permanent deformation and fatigue cracking. This improvement is not just because of the modification of the material strength, but also by the modification of the material behavior in resisting pavement distresses [11].

Asphalt plants usually have special components to add fibers and other additives to the hot mix asphalt during its productions. If asphalt plants have not these components, the fibers addition could be done manually.

Life Cycle Cost Analysis (LCCA) have been used to assess the costs of rehabilitation activities using hot mix asphalt with and without polypropylene and aramid fibers. The addition of fibers at $0.45 \mathrm{~kg} /$ ton can result in a saving in the net present worth dollar value ranges from $\$ 14,000$ to $\$ 50,000$ per mile/lane or a reduction in the equivalent annual cost ranges from 750 to 2000 mile/lane/ year [12].

\section{Objective and scope}

The objective of this study was to evaluate the benefits of the polypropylene and aramid fibers in improving the performance characteristics of a modified asphalt mixture used in Brazil. A conventional dense-graded HMA used in Sao Paulo was used for this purpose. The laboratory experimental program included the evaluation of: resistance to moisture-induced damage, resilient modulus, dynamic modulus; flow number test; fatigue, and fracture energy using the semi-circular test. Two asphalt mixtures were used in the laboratory program: a control HMA with no fibers, and a fiber reinforced HMA, which contained the fibers.

\section{Materials}

The dense graded control HMA used had a maximum aggregate size of $12.5 \mathrm{~mm}$ Table 1 shows the aggregate gradation requirement (per Brazilian DNIT - National Department of Transportation Infrastructure specifications) and the final obtained gradation for this study. It was used a conventional asphalt binder, PG 70-16 (ASTM D6373). Table 2 shows the mix design of the HMA, performed by the Marshall method with 75 blows and Table 3 present the asphalt binder characteristics.

The fibers used in this study were a blend of aramid and polypropylene fibers, designed for use in hot mix asphalt applications. Fig. 1 shows an image of these synthetic fibers and Table 4 shows their physical properties.

The fibers were added to the HMA with the same characteristics of the control mixture described before, at the rate of $0.5 \mathrm{~kg} /$ metric ton of total mix. Fibers were added to hot aggregates and a short dry mix was performed. After that, hot asphalt binder was added and mixed. Fig. 1 shows the fiber addition to hot aggregates at the laboratory.

\section{Laboratory tests, results and analyses}

\subsection{Resistance to moisture induced damage}

Certain HMA may be sensitive to presence of water, accelerating the process of failure of asphalt pavements. The AASHTO T 283 gives guidelines to determine if HMA materials may be subject to stripping and to measure the effectiveness of additives used to enhance this behavior.

This test is performed by compacting specimens to an air void level of $7 \pm 1 \%$. Three specimens are used as a control and tested without moisture conditioning and three specimens are selected to be conditioned by saturating with water undergoing a freeze cycle and subsequently having a warm-water soaking cycle. After this process, specimens are tested for indirect tensile strength. The tensile strength of the conditioned specimen is compared to the control specimens to determine the tensile strength ratio (TSR).

Table 5 shows results of moisture induced damage obtained for the control and a fiber-reinforced HMA. It is noted that both passed the minimum requirement that is $70 \%$, usually adopted in Brazilian specifications. The Tensile Strength of the HMA with fibers was about $20 \%$ greater, when compared to Tensile Strength of the control HMA, for both conditioning situations. Thus, the HMA with fibers would stand for higher stress levels in asphalt pavements.

\subsection{Resilient modulus test}

For the Resilient Modulus test, a repeated-load indirect tension of fixed amplitude, with a duration of $0.1 \mathrm{~s}$ followed by a rest period of $0.9 \mathrm{~s}$, is applied to the test specimen. During testing, the specimen is subjected to a dynamic cyclic stress and a constant stress (seating load). The resulting horizontal deformation of the specimen is measured and the resilient modulus is calculated. The Resilient Modulus is used in the evaluation of materials quality and as input for pavement design, evaluation and analysis (ASTM D 7369-09).

Table 6 shows average results of resilient modulus obtained from nine specimens for each condition, at $25^{\circ} \mathrm{C}\left(77^{\circ} \mathrm{F}\right)$. The resilient modulus for the HMA with fibers was $15 \%$ higher than the control HMA, indicating an increase of stiffness when fibers are added, which could lead to better asphalt pavements to withstand rutting. The standard deviation results show that this difference is statistically significant. 
Table 1

Aggregate gradation of the dense HMA.

\begin{tabular}{llllll}
\hline \multirow{2}{*nnnn}{ Sieves } & & & \multicolumn{3}{l}{ Hot mix asphalt gradation } \\
\cline { 5 - 6 }$\#$ & $\mathrm{~mm}$ & & MIN & MAX & Used in Study \\
\hline $1^{\prime \prime}$ & 25.0 & & 100 & 100 & 100 \\
$3 / 4^{\prime \prime}$ & 19.0 & & 100 & 100 & 100 \\
$1 / 2^{\prime \prime}$ & 12.5 & & 80 & 100 & 85.1 \\
$3 / 8^{\prime \prime}$ & 9.5 & & 70 & 90 & 78.3 \\
$\mathrm{~N}^{\circ} 4$ & 4.75 & & 50 & 70 & 53.1 \\
$\mathrm{~N}^{\circ} 10$ & 2.00 & & 33 & 48 & 37.9 \\
$\mathrm{~N}^{\circ} 40$ & 0.42 & & 15 & 25 & 22.5 \\
$\mathrm{~N}^{\circ} 80$ & 0.18 & 8 & 17 & 14.6 \\
$\mathrm{~N}^{\circ} 200$ & 0.075 & 4 & 10 & 8.6 \\
\hline
\end{tabular}

Table 2

HMA design results.

\begin{tabular}{ll}
\hline Asphalt binder content (Pb) (\%) & 4.7 \\
Bulk specific gravity for aggregate blend (Gsb) & 2.677 \\
Bulk specific gravity of compacted mixture (Gmb) & 2.379 \\
Theoretical maximum specific gravity of loose mixture (Gmm) & 2.478 \\
Air void content (VA) (\%) & 4.0 \\
Volume of voids in mineral aggregate (Vma) (\%) & 14.1 \\
Volume of aggregate (Vsb) (\%) & 71.6 \\
Filler asphalt ratio (f/a) & 1.95
\end{tabular}

Table 3

Asphalt binder characteristics.

\begin{tabular}{lll}
\hline Charactersistic & Results & Standard \\
\hline Penetration $(\mathrm{dmm})$ & 33 & (ASTM D 5) \\
Softening point $\left({ }^{\circ} \mathrm{C}\right)$ & 54 & (ASTM D 36) \\
Density $\left(\mathrm{g} / \mathrm{cm}^{3}\right)$ & 1.013 & (ASTM D 70) \\
Brookfield viscosity @ $135^{\circ} \mathrm{C}$ & 505 & (ASTM D 4402) \\
Brookfield viscosity @ $150^{\circ} \mathrm{C}$ & 244 & \\
Brookfield viscosity @ $177^{\circ} \mathrm{C}$ & 85 & \\
Performance grade & $70-16$ & (ASTM D 6373) \\
$\mathrm{G}^{*} /$ send, virgin $(\mathrm{kPa})$ & 1.107 & (ASTM D 7175) \\
$\mathrm{G}^{*} /$ send, RTFOT $(\mathrm{kPa})$ & 2.245 & \\
$\mathrm{Jnr}\left(\mathrm{kPa}{ }^{-1}\right.$ ) & 4.54 & (AASHTO TP 70) \\
Elastic recovery $(\%)$ & 0.0 & \\
\hline
\end{tabular}

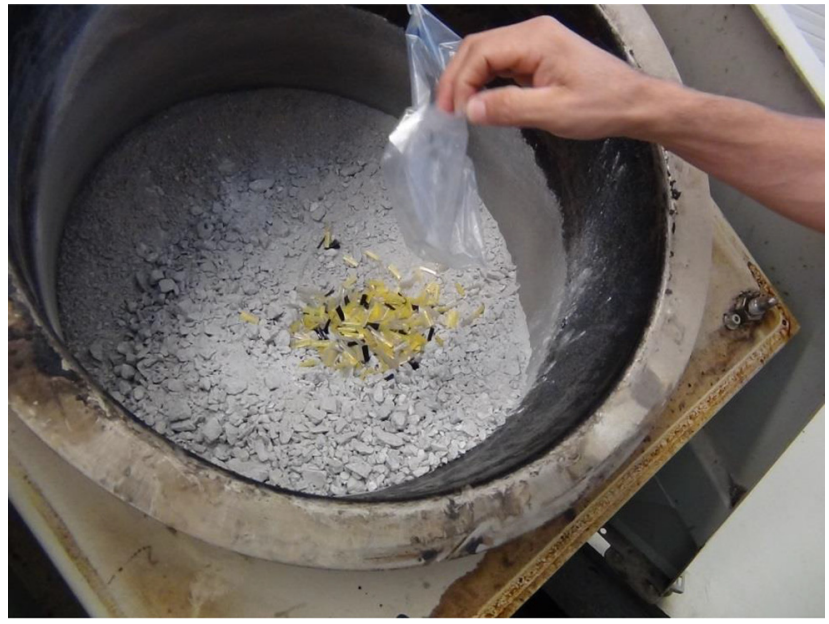

Fig. 1. Addition of fibers to the hot aggregates, before asphalt binder addition.

\section{3. $E^{*}$ dynamic modulus test}

The stress-to-strain relationship for an asphalt mixture under a continuous sinusoidal loading is defined by its complex dynamic modulus $\left(E^{*}\right)$. In the Mechanistic Empirical Pavement Design Guide
Table 4

Polypropylene and aramid fibers characteristics.

\begin{tabular}{lll}
\hline & Materials & \\
\cline { 2 - 3 } & Polypropylene & Aramid \\
\hline Property & Twisted fibrilated & Multifilament \\
& fiber & fiber \\
Specific gravity & 0.91 & 1.45 \\
Tensile strenght, MPa (ksi) & $483(70)$ & $3000(435)$ \\
Length, mm (in.) & $19(0.75)$ & $19(0.75)$ \\
Acid/alkali resistance & Inert & Good \\
Decomposition temperature ${ }^{\circ} \mathrm{C}$, & $157(315)$ & $>450(842)$ \\
$\left({ }^{\circ} \mathrm{F}\right)$ & & \\
\hline
\end{tabular}

Table 5

Resistance to moisture induced damage of control HMA and HMA with fibers.

\begin{tabular}{llll}
\hline & \multicolumn{2}{l}{ Tensile strenght, MPa (ksi) } & $\begin{array}{l}\text { Tensile strenght } \\
\text { retained }(\%)\end{array}$ \\
\cline { 2 - 3 } & $\begin{array}{l}\text { Without moisture } \\
\text { condition }\end{array}$ & $\begin{array}{l}\text { With moisture } \\
\text { condition }\end{array}$ & \\
\hline HMA control & $1.70(0.25)$ & $1.67(0.24)$ & 98 \\
HMA with fibers & $2.05(0.30)$ & $1.96(0.28)$ & 96 \\
\hline
\end{tabular}

Table 6

Resilient Modulus at $25^{\circ} \mathrm{C}\left(77^{\circ} \mathrm{F}\right)$ results for HMA with and without fibers.

\begin{tabular}{lll}
\hline & $\begin{array}{l}\text { Average resilient } \\
\text { modulus, MPa (ksi) }\end{array}$ & $\begin{array}{l}\text { Standard } \\
\text { deviation }\end{array}$ \\
\hline HMA control & $8392(1217)$ & $829\left(\begin{array}{lll}1 & 2 & 0\end{array}\right)$ \\
HMA with fibers & $9651(1400)$ & $669\left(\begin{array}{lll}2 & 0 & 3\end{array}\right)$ \\
\hline
\end{tabular}

(MEPDG), the $E^{*}$ of an asphalt mixture is determined using AASHTO TP 62-09. The test is done using a controlled sinusoidal stress that produces strains smaller than 150 micro-strain. For each mix, nine specimens, $100 \mathrm{~mm}$ in diameter and $150 \mathrm{~mm}$ in height, were tested at $4.4,21.1,37.8$ and $54.4^{\circ} \mathrm{C}\left(40,70,100\right.$ and $\left.130{ }^{\circ} \mathrm{F}\right)$ and $25,10,5,1,0.5$ and $0.1 \mathrm{~Hz}$ loading frequencies.

Master curves were constructed at a reference temperature of $21^{\circ} \mathrm{C}\left(70^{\circ} \mathrm{F}\right)$ for both, the control and fiber-reinforced HMA. Fig. 2 shows that the HMA reinforced with fibers had moduli values $30 \%$ higher than the control HMA at high temperatures or low frequencies. At higher temperatures, the binder becomes softer, the aggregates dominate the elastic behavior of the asphalt mixtures, and the reinforcement effect of the fibers can enhance the modulus values at higher temperatures [11]. In other words, the fibers could contribute, at higher temperatures, to asphalt pavements in better resisting rutting or permanent deformation.

\subsection{Flow number test}

The flow number test can be used to evaluate rutting resistance of hot mix asphalt. A repeated compressive stress pulse is applied to a HMA specimen, producing permanent strain in it, which is recorded for each load cycle. The test is performed at the temperature of $54.4^{\circ} \mathrm{C}\left(130^{\circ} \mathrm{F}\right)$. The point in the permanent strain curve where the rate accumulation of permanent strain reaches a minimum value (and then increasing rapidly) has been defined as the flow number.

Fig. 3 shows an example of a permanent strain versus the number of load cycles curves obtained during the flow number test. It can be noted that HMA reinforced with fibers could withstand a higher number of cycles, when compared to the control HMA, at the same strain level. Table 7 shows average flow numbers of both asphalt mixtures, obtained from nine specimens at each condition. 


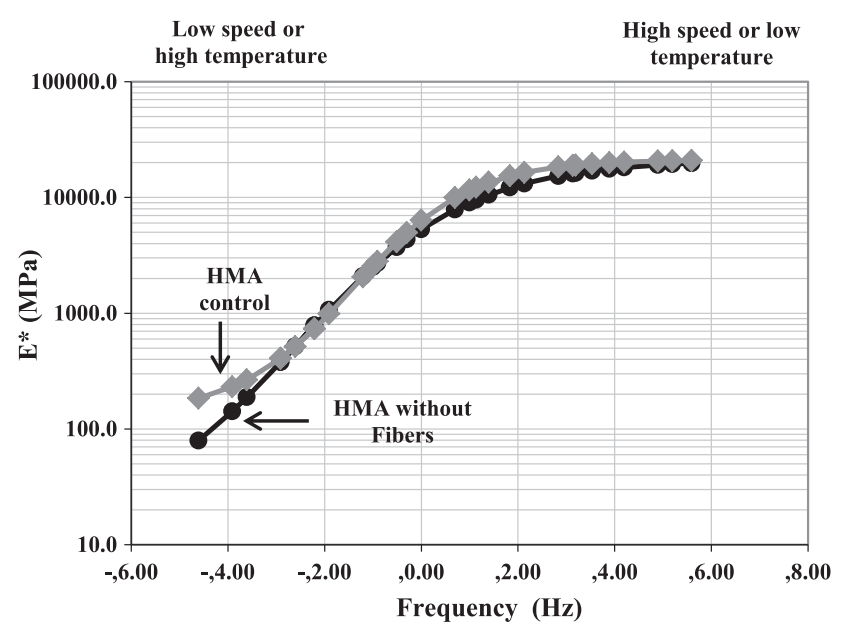

Fig. 2. Master curves of HMA with and without fibers.

I presents, at the right column, the expected traffic that will develop rutting of $12.5 \mathrm{~mm}$ in asphalt pavements [13]. Once again, the HMA reinforced with fibers can resist over two times the traffic that the control HMA can withstand.

\subsection{Fatigue cracking test}

Fatigue is caused in asphalt pavement as a result of traffic induced tensile and shear stresses in the bound layers. Throughout its service life, fatigue will induce cracks where critical tensile strains and stresses occur. To predict the number of load repetitions to fatigue cracking can be used the Eq. (1).

$N_{f}=k_{1}\left(\frac{1}{\varepsilon_{t}}\right)^{k_{2}}$

where:

$N_{f}=$ number of repetitions to fatigue cracking,

$\varepsilon_{t}=$ tensile strain at the critical location,

$k_{1}, k_{2}=$ laboratory calibration parameters.

In this study, beam specimens were used for the four-point bending fatigue tests with $4.0 \%$ of air voids and dimensions of $63.5 \mathrm{~mm}$ (2.5 in.) wide, $50.8 \mathrm{~mm}$ (2.0 in.) high and $380 \mathrm{~mm}$ (15.0 in.) long. The test was done at $21^{\circ} \mathrm{C}\left(70^{\circ} \mathrm{F}\right)$ and applying a cyclic load at the frequency of $10 \mathrm{~Hz}$. The flexural stiffness

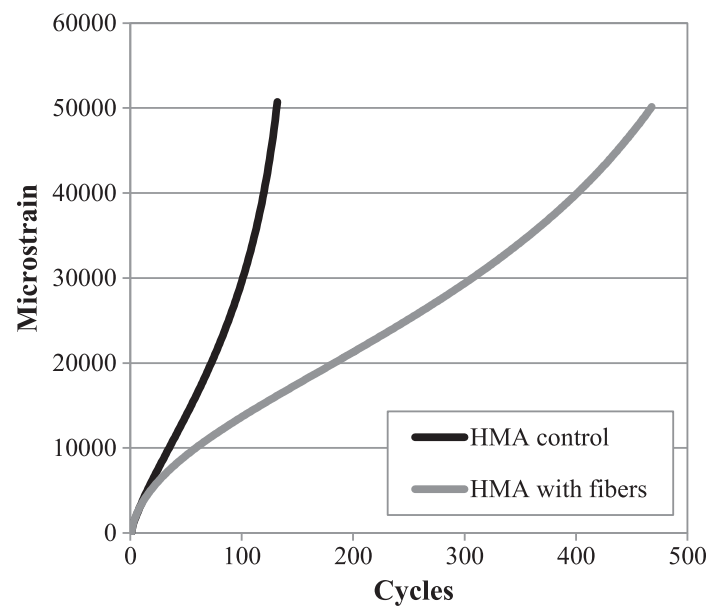

Fig. 3. Permanent strain curve of HMA during flow number test. calculated according Eqs. (2)-(4). The flexural stiffness at the 50th cycle is recommended to be used as the initial stiffness of the specimen and the reduction of flexural stiffness is calculated and recorded during the test. Failure was defined as the number of cycles corresponding to $50 \%$ reduction in the initial stiffness, as required by AASHTO TP8.

$$
\begin{aligned}
& \sigma_{t}=\frac{S w \cdot P \cdot 1000000}{w h^{2}} \\
& \varepsilon_{t}=\frac{12 \delta \cdot h \cdot 1000000}{\left(3 S_{w}^{2}-4 L_{w}^{2}\right)} \\
& S=\frac{\sigma_{t}}{\varepsilon_{t}}
\end{aligned}
$$

where:

$$
\begin{aligned}
& \text { S = flexural stiffness }(\mathrm{MPa}) ; \\
& \sigma_{\mathrm{t}}=\text { tensile stress }(\mathrm{kPa}) ; \\
& \varepsilon_{\mathrm{t}}=\text { tensile strain }(\mu \varepsilon) ; \\
& \mathrm{Sw}=\text { support span width }(\mathrm{mm}) ; \\
& \mathrm{Lw}=\text { loading span width }(\mathrm{mm}) ; \\
& \mathrm{P}=\text { peak force }(\mathrm{kN}) ; \\
& \text { w = average beam width }(\mathrm{mm}) ; \\
& \mathrm{h}=\text { average beam height }(\mathrm{mm}) ; \\
& \delta=\text { peak deflection at the center of beam }(\mathrm{mm}) ;
\end{aligned}
$$

Twelve specimens were used in the four-point bending fatigue test at different strain levels, from 300 to $650 \mu \varepsilon$. Fig. 4 shows fatigue relationship of control HMA and HMA fiber reinforced and Table 8 shows the regression equations. Results show that the fatigue life is higher for the HMA with fibers at moderate to low strain levels. This behavior suggests that HMA with fibers will perform better in roads with moderate to low deflection levels. The results at the highest strain levels need further evaluation, but it is realistic to mention that this comparison is approximate since the initial stiffness of both mixtures are not the same. In addition, it is noted that the final stiffness of the fiber-reinforced HMA mixture is higher than the control, indicating better general performance. It is also worth mentioning that the higher regression coefficient $\left(\mathrm{R}^{2}\right)$ for the fiber-reinforced mixture may be also indicative of more homogeneous mixture behavior among the various beams that were produced and tested.

\subsection{Cracking resistance}

The semicircular bend (SCB) test has been used to determine the fracture resistance parameters of asphalt mixtures at intermediate temperatures. These parameters describe the fracture and fatigue resistance of asphalt mixtures. Three specimens of a thickness of $50 \mathrm{~mm}$ and a half-diameter of $150 \mathrm{~mm}$ were used in this test, as shown in Fig. 5. The load was applied at a constant displacement rate of $1 \mathrm{~mm} / \mathrm{min}$ at the temperature of $21^{\circ} \mathrm{C}$.

Fig. 6 shows an example of the stress-strain curves obtained for the semicircular bend test for both mixtures. It can be noted that the area under the curve is higher for the HMA reinforced with fibers, which means a better ability to absorb energy due to fracture. Table 9 presents average results of the SCB test, performed in nine specimens at each condition. I is noted that the HMA reinforced with fibers had an area under the stress-strain curve 30\% higher, indicating a better resistance to crack propagation. This means that the HMA with fibers, used as a pavement overlay, could better resist reflective cracking. 
Table 7

Flow number of HMA with and without fibers, and expected traffic to develop rutting of $12.5 \mathrm{~mm}$.

\begin{tabular}{|c|c|c|c|c|}
\hline & \multicolumn{2}{|c|}{ Flow Number } & \multirow[t]{2}{*}{ Cycles to $50,000 \mu \varepsilon$} & \multirow[t]{2}{*}{ Millions equivalent standard axle } \\
\hline & Average & St. Dev. & & \\
\hline HMA control & 53 & 13.7 & 178 & 5.1 \\
\hline HMA with fibers & 162 & 8.6 & 463 & 13.6 \\
\hline
\end{tabular}

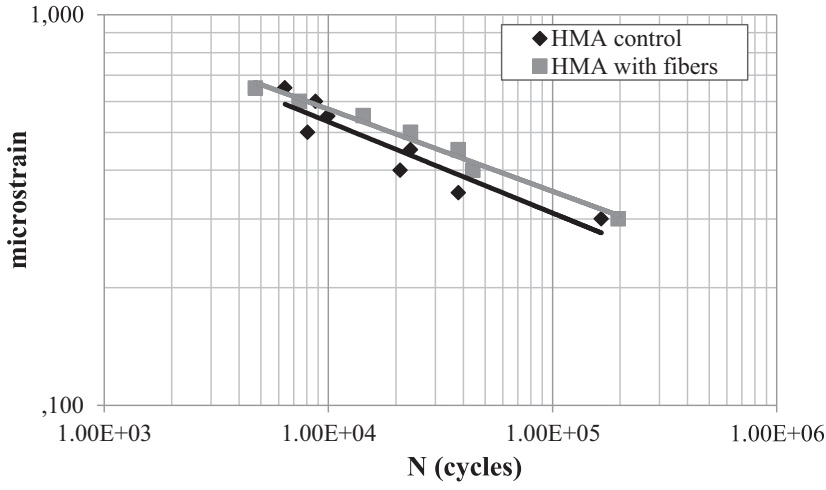

Fig. 4. Fatigue relationship for both mixtures at $21^{\circ} \mathrm{C}$.

\section{Conclusions}

The results of the laboratory tests executed in this study showed that the addition of polypropylene and aramid fibers to hot mix asphalts improves its mechanical characteristics. Below are the main conclusions of this study:

- Regarding the resistance to the potential of moisture induced damage, the HMA with fibers had similar behavior when compared to control HMA. It is noted that the HMA mixture is of high quality used on typical highway conditions in Sao Paulo. So these positive results are expected. However, the tensile strength values were about $20 \%$ higher in both conditions (before and after moisture conditioning) when fibers were added to the HMA. It can be stated that the fiber reinforced HMA would perform equally or better in this category.

- The resilient modulus at $25^{\circ} \mathrm{C}$ was $15 \%$ higher for the HMA with fibers, when compared with control HMA. For the dynamic modulus test, the fiber reinforced HMA had $30 \%$ higher $E^{*}$ at elevated temperatures, which means that this mixture can better resist rutting or permanent deformation in asphalt pavements.

- For the flow number test, the HMA with fibers showed lower permanent strain accumulation compared to the control HMA and also had higher flow number indicating better mix stability against shear deformation. These results show that the use of fibers in HMA could lead to better asphalt pavement resistance to rutting.

- Fatigue cracking tests showed that the HMA with fibers have better fatigue cracking resistance than the control HMA at moderate to low strain levels. This means (results pertaining to this test) that the use of fibers would be mostly beneficial in moderate to low deflection pavements.

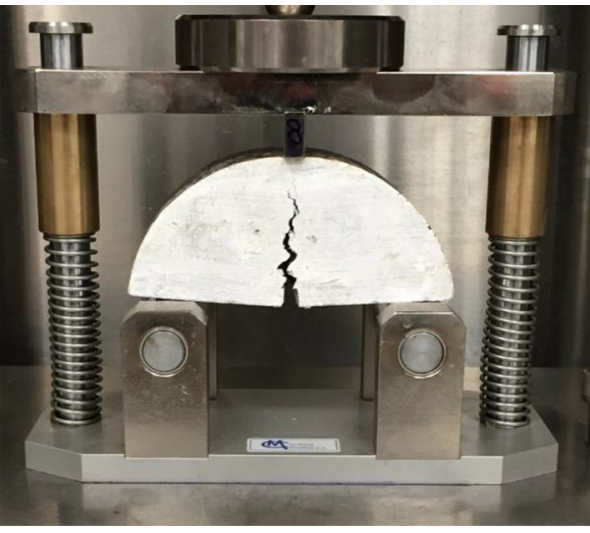

Fig. 5. Semicircular bend (SCB) test at intermediate temperatures.

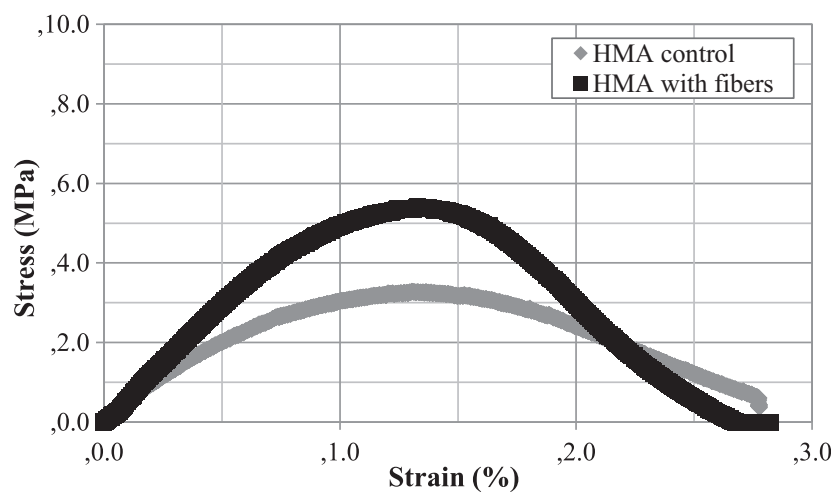

Fig. 6. Stress strain curve for control HMA and HMA with fibers.

Table 9

Semicircular bend test results for control HMA and HMA with fibers.

\begin{tabular}{clll}
\hline & & $\begin{array}{l}\text { HMA } \\
\text { control }\end{array}$ & $\begin{array}{l}\text { HMA with } \\
\text { fibers }\end{array}$ \\
\hline Displacement, mm (in) & Average & $3.44(0.135)$ & $3.61(0.142)$ \\
& St. Dev. & $0.9(0.03)$ & $0.33(0.01)$ \\
Strain (\%) & Average & 4.68 & 4.89 \\
& St. Dev. & 1.22 & 0.44 \\
Force, N (kip) & Average & $2881(0.65)$ & $3771(0.85)$ \\
Stress, MPa (ksi) & St. Dev. & $191(0.04)$ & $220(0.05)$ \\
& Average & $5.59(0.81)$ & $7.28(1.06)$ \\
Area under the & St. Dev. & $0.32(0.05)$ & $0.42(0.06)$ \\
stress-strain curve & Average & 7.25 & 9.57 \\
& St. Dev. & 1.63 & 1.00
\end{tabular}

Table 8

Results of the four point bending test.

\begin{tabular}{|c|c|c|c|c|c|}
\hline & \multicolumn{3}{|c|}{ Regression equation } & \multirow[t]{2}{*}{ Flexural stiffness at 50th cycle MPa (ksi) } & \multirow[t]{2}{*}{ Flexural stiffness at final cycle MPa (ksi) } \\
\hline & $\mathrm{k} 1$ & $\mathrm{k} 2$ & $\mathrm{R} 2$ & & \\
\hline HMA without fibers & $1.81 \mathrm{E}+14$ & -3.751 & 0.88 & $9859(1430)$ & $5595(811)$ \\
\hline HMA with fibers & $7.01 E+16$ & -4.654 & 0.98 & $11,825(1715)$ & $5887(854)$ \\
\hline
\end{tabular}


- The semicircular bending test was performed at intermediate temperatures of $21^{\circ} \mathrm{C}$. It was noted that the HMA mixture with fiber has a better ability to absorb energy, up to and due to fracture, compared to the control HMA. Therefore, overlays built with fiber reinforced HMA could better resist and withstand reflective cracking.

Finally, it is concluded that the addition of blended fibers of polypropylene and aramid to hot mix asphalt enhance its mechanical properties. The use of fiber reinforced HMA in new pavements or as an overlay could retard the development of asphalt pavement distresses, and extending its service life.

\section{Conflict of interest}

None.

\section{Acknowledgement}

The authors would like to acknowledge Heavy Equipment Solutions Inc., Quebec, Canada for providing the fibers.

\section{References}

[1] C.L. Monismith, N.F. Coetzee, Reflection cracking: analysis, laboratory studies and design considerations, J. Assoc. Asphalt Pav. Technol. 49 (1980) 268-313.
[2] R.S. McDaniel, NCHRP Synthesis 475: Fiber Additives in Asphalt Mixtures, Transportation Research Board of the National Academies, Washington, D.C., 2015.

[3] W. Shaopeng, Y. Qunshan, L. Ning, Y. Hongbo, Effects of Fibers on the Dynamic Properties of Asphalt Mixtures, in Fibers of Wuhan Universtity of Technology Materials Science Edition, Vol. 22, 2007, pp. 733-736.

[4] J.P. Serfass, J. Samanos, Fiber-modified asphalt concrete characteristics, applications and behavior, J. Assoc. Asphalt Pav. Technol. 65 (1996) 193-230.

[5] S.J. Lee, J.P. Rust, H. Hamouda, Y.R. Kim, R.H. Borden, Fatigue cracking resistance of fiber-reinforced asphalt concrete, Text. Res. J. 75 (2) (2005) 123-128.

[6] M.A. Cleven, Investigation of the Properties of Carbon Fiber Modified Asphalt Mixtures M.S. thesis, Department of Chemical Engineering, Michigan Technological University, Houghton, MI, 2000.

[7] S.M. Abtahi, M. Sheikhzadeh, S.M. Hejzi, Fiber reinforced asphalt-concrete - a review, Constr. Build. Mater. 24 (2010) 871-877.

[8] A. Mahrez, M.R. Karim, H.A. Katman, Prospect of using glass fiber reinforced bituminous mixes, J. Eastern Asia Soc. Transport. Stud. 5 (2) (2003) 784-807.

[9] S. Tapkin, The effect of polypropylene fibers on asphalt performance, Build. Environ. 43 (6) (2008) 1065-1074.

[10] T. Jiang, R.S. Mcdaniel, Application of Cracking and Seating and Use of Fibers to Control Reflective Cracking. In: Transportation Research Record: Journal of the Transportation Research Board, No. 1388, Transportation Research Board of the National Academies, Washington, D.C., 1993, pp. 150-159.

[11] K.E. Kaloush, K.P. Biligri, W.A. Zeiada, C. Cary, S. Dwivedi, J. Reed, C. Rodezno Evaluation of fiber-reinforced asphalt mixtures using advanced material characterization tests, J. Test. Eval. 38 (4) (2010) 1-12.

[12] W. Zeiada, K. Kaloush, S. Underwood, Cost Analysis of Fiber-Reinforced Pavements. 2nd IRF Asia Regional Congress and Exhibition, October 16-20, 2016, Kuala Lumpur, Malaysia.

[13] R. Bonaquist, NCHRP Report 691: Mix Design Practices for Warm Mix Asphalt, Transportation Research Board of the National Academies, Washington, D.C. 2011. 